\title{
ION IMPLANTATION IN SEMICONDUCTORS
}

\author{
James W. Mayer \\ California Institute of Technology \\ Pasadena, California 91109
}

\section{ABSTRACT}

Ion implantation is being applied extensively to silicon device technology. Two principle features are utilized: 1) charge control in MOS structures for threshold shift, autoregistration, and complementary wells and 2) distribution control in microwave and bipolar structures. Another feature that has not been extensively exploited is to combine the advantages of the high resolution capabilities of electric beam pattern delineation with the low lateral spread inherent in the implantation process. This talk reviews some of the general features of the characteristics of implanted layers in terms of depth distribution, radiation damage and electron activity. Implantation processes in silicon are reasonably well understood. There remain areas which require further clarification. For compound semiconductors, particularly GaAs, implantation techniques offer attractive possibilities for the fabrication of high frequency devices. In these materials, the substrate temperature during implantation and the dielectric coating required to prevent dissociation during thermal anneal play major roles.

\section{INTRODUCT ION}

Ion implantation is the introduction of atoms into a solid substrate by bombardment with ions in the $\mathrm{keV}$ to $\mathrm{MeV}$ energy range. The basic concepts of implantation processes have been treated in conferences and books $(1-4)$. It was early recognized that this technique provides the possibility of introducing a wide selection of atomic species and also external control of both the number of atoms per $\mathrm{cm}^{2}$ introduced into the semiconductor and the depth distribution of the implanted species. This is in contrast to diffusion processes where temperature governs the surface concentration and time and temperature determine the depth distribution.

The initial impact on silicon technology was in charge control. It has been possible to control the number of dopant atoms per $\mathrm{cm}^{2}$ to about $1 \%$ over the surface of a wafer, and to control the number within $3 \%$ from wafer to wafer. This in combination with the fact that simple masking techniques can be used to define the geometrical area of the implanted region led to extensive applications to MOS technology (5). An extension of this work has led to the use of electron beams to expose photoresist so that one micron gate lengths can be fabricated for
$N$-channel enhancement-depletion mode FET's (6).

The distribution control inherent in the implantation process has been utilized in fabricating IMPATT type devices $(7,8)$. Here multiple implantations are performed at different energies and ion doses to achieve the desired dopant profile.

There are limitations to the implantation process. At energies $\lesssim 300 \mathrm{keV}$, the range of the implanted ion is typically less than one micron and often of the order of a few tenths of microns. Diffusion steps are necessary to achieve greater depths. Lattice disorder and radiation damage induced defects are caused by the implanted atom as it comes to rest in the semiconductor. Although implantation is considered as a room temperature process, it is necessary to thermally anneal the samples after implantation. Often these anneal temperatures are comparable to those used in diffusion.

\section{IMPLANTATION IN SILICON}

Silicon provides an ideal host for studying the basic parameters and concepts involved in the implantation process. The parameters are: substrate temperature during implantation, anneal temperature, total dose of ions per $\mathrm{cm}^{2}$ and dose rate, beam energy and beam species. All of these parameters should be considered when evaluating implantation behavior in any semiconductor. For silicon boron, phosphorus and, more recently, arsenic are generally implanted at room temperature and annealed to about $900^{\circ} \mathrm{C}$ to achieve the maximum electrical activity. Where aluminum metallization is employed prior to implantation, anneal temperatures around $550^{\circ} \mathrm{C}$ are used with some loss in dopant efficiency.

Range Distributions

If channeling effects are negligible the depth distribution of implanted ions is roughly Gaussian and can be characterized by a mean projected range $R_{p}$ and a standard deviation $\Delta R_{p}$ about the mean $(4)$. Approximations and rules of thumb have been given by Schiott (9) and tabulations by Johnson and Gibbons (10). These provide reasonable estimates for the projected range (11). In most cases there is no major change in the peak of the distribution following anneal at $900^{\circ} \mathrm{C}(12)$. However, the width of the 
profile is generally broader than predicted and there are often tails in the distribution. In device applications where the depth distribution is important, it is generally necessary to make an experimental determination of the depth profile.

The crystalline rows and planes can steer or "channel" the implanted ions significantly deeper into the crystal than in amorphous targets (4). Channeled distributions for arsenic (13) and phosphorus $(14,15)$ implantations have been measured by $\mathrm{C}-\mathrm{V}$ techniques. The maximum range to which the ions penetrate is determined by the incident energy and orientation of the silicon and can be a factor of ten deeper than the projected range $R_{p}$ for incidence away from any major crystal axis. Conditions are very stringent for the incident ion to remain channeled throughout its trajectory. The shape of the depth distribution is strongly influenced by lattice disorder, by the amount of oxide layer on the surface, and by any misorientation between the incident ion beam and crystal axis $(14,15)$. Because of the stringent conditions required to obtain well-behaved channeling distributions, there are serious limitations on the use of this technique in general fabrication steps.

Lattice Disorder and Radiation Damage

Over the past three or four years one of the major efforts has been to characterize the amount and the nature of lattice disorder produced by energetic ions (1-4). The amount of lattice disorder depends on ion mass and energy, substrate temperature during implantation, dose rate, and dose. It is a fascinating and complex field.

Some simple approximations can be made. For low dose $\left(\approx 1012 / \mathrm{cm}^{2}\right)$ implantations, there are strong correlations in defect species between ion implanted and fast neutron irradiated silicon (16). Most of the gross disorder anneals out at temperatures around $300^{\circ} \mathrm{C}$ but higher temperatures are required to remove the compensating defects. At higher ion doses (1014. $10\left(5 / \mathrm{cm}^{2}\right)$ an amorphous layer is formed (4). During anneal at temperatures of about $550^{\circ} \mathrm{C}$, this amorphous layer recrystallizes epitaxialiy on the underlying crystalline material. There are a significant number of defects in the recrystallized layer (17). The lifetime of minority carriers is very sensitive to the presence of defects. With increasing ion dose, higher anneal temperatures $\left(\gtrsim 900^{\circ} \mathrm{C}\right)$ are required to recover carrier lifetimes (18).

In general, then, it is desirable to use as high an anneal temperature as possible to remove radiation induced defects. Temperatures of 900 to $950^{\circ} \mathrm{C}$ are commonly employed. With low dose implants typical of MOS technology temperatures below $550^{\circ} \mathrm{C}$ can be employed.

\section{Lattice Location and Electrical Behavior}

Following implantation and anneal, n-type

(Group V) dopants occupy substitutional sites.
The behavior of Group III elements is much more complex (4). Boron, for example, has been found to move off substitutional sites during anneal and temperatures of about $900^{\circ} \mathrm{C}$ are required to obtain a high substitutional fraction (4).

Perhaps the most thoroughly investigated aspect of ion implantation in silicon is the electrical behavior of the implanted layer. In general, Hall effect measurements in combination with layer removal techniques have been made. The number of carriers per $\mathrm{cm}^{2}$ is determined as a function of anneal temperature for various doses of implanted ions (1-4).

A rough rule is that after anneal at temperatures of $900^{\circ} \mathrm{C}$ to remove radiation damage defects, all the implanted dopant atoms become electrically active (4). This behavior (except for arsenic) holds for cases where the concentration of the implanted species is less than the equilibrium solubility at the anneal temperature. For arsenic, the maximum concentration of electrons is about $1020 / \mathrm{cm}^{3}$, a value well below the maximum substitutional concentration. In cases where an amorphous layer is formed, there is a pronounced anneal stage at $550^{\circ} \mathrm{C}$. This fact is often utilized to obtain high electrical activity at low anneal temperatures (19).

\section{IMPLANTATION IN GaAs}

The natural extension of the work in silicon is to investigate implantation processes in compound semiconductors. For these materials, diffusion technology is at a rather primitive level as compared to silicon, so that implantation would not have to compete with a well established technology. In addition, the higher electron mobility in GaAs, for example, lends itself to high frequency device concepts.

The major constraint is that compound semiconductors tend to dissociate when annealed to the temperatures required to remove damage induced defects. The simplest method of avoiding this dissociation is to encapsulate the implanted samples with a dielectric coating. Some of the initial efforts in the evaluation of implanted layers in GaAs were to determine if good electrical activity could be obtained without encapsulation of the layer (20). This approach was not successful.

Anneal temperatures of 800 to $900^{\circ} \mathrm{C}$ are generally required to obtain the maximum number of carriers per $\mathrm{cm}^{2}$ in the implanted layers (21). These anneal temperatures and encapsulation with $\mathrm{SiO}_{2}$ are generally sufficient to achieve good electrical activity for $p$-type dopants. The carrier concentrations in the implanted layer are close to the solubility level.

The initial results obtained on implanted layers in GaAs for n-type dopants were disappointing in that very low electrical activity was found (22). More recently it has been observed that good electrical activity can be obtained by proper choice of the implantation temperature and encapsulating layer (23). In this case silicon nitride was used as the encapsulating layer to 
prevent out-diffusion of $\mathrm{Ga}$ and substrate temperatures of 150 to $300^{\circ} \mathrm{C}$ were used to reduce the residual disorder. The maximum concentration of electrons was comparable to that obtained by doping GaAs with Te during crystal growth.

The results from studies of implantation of $p$ - and $n$-type dopants in GaAs indicate that good electrical activity can be obtained. Rather high anneal temperatures of $800-900^{\circ} \mathrm{C}$ and encapsulating layers are required. In spite of these difficulties, one can now anticipate use of implantation in GaAs device applications.

\section{ACKNOWLEDGMENTS}

This discussion was taken in large from F. H. Eisen and J. W: Mayer, "Ion Implantation and Channeling" to appear in "Treatise on Solid State Chemistry," Vo1. 5, Chapter 8, Edited by B. Hannay (Plenum Press).

\section{REFERENCES}

1. F. H. Eisen and L. T. Chadderton, eds., "Ion Implantation," (Proceedings of the First International Ion Implantation Conference), Gordon and Breach, New York 1971.

2. I. Ruge and J. Graul, eds., "Ion Implantation in Semiconductors," (Proceedings of the Second International Ion Implantation Conference), Springer-Verlag, Berl in 1971.

3. B. L. Crowder, ed., "Proceedings of the Third International Implantation Conference," Plenum Press, New York 1973.

4. J. W. Mayer, L. Eriksson, and J. A. Davies, "Ion Implantation in Semiconductors," Academic Press, New York 1970.

5. See for example, International Electron Device Meeting, Washington, Dec. 1972.

6. F. Fang, M. Hatzakis, C. H. Ling, "Electron Beam Fabrication of Ion Implanted High Performance FET Circuits," in the Twelfth Symposium on Beam Technology, May 1973; J. Vacuum Sci. and Tech., Dec. 1973.

7. T. E. Seidel, R. E. Davies, and D. E. Iglesias, "Double-Drift-Region Ion-Implanted Millimeter-Wave IMPATT Diodes, "Proc. IEEE, Vol. 69, pp. 1222-1228, Aug. 1971.

8. T. T. Fong, R. S. Ying, and D. H. Lee, "Ion Implanted X-band IMPATT/TRAPATT Back-toBack Diodes" Proc IEEE, Vo1. 61, pp. 10441045, July 1973.

9. H. E. Schiott, "Approximations and Interpolation Rules for Ranges and Range Stragglings," Rad. Eff., Vol. 6, pp. 107-114, 1970.

10. W. S. Johnson and J. F. Gibbons, "Projected Range Statistics in Semiconductors," distr. by Stanford University Bookstore 1969.

11. B. L. Crowder, "The Influence of the Amorphous Phase on Ion Distributions and Annealing Behavior of Group III and Group V Ions Implanted in Silicon," J. Electrochem. Soc., Vo1. 118, pp. 943-952, 1971.

12. J. F. Ziegler, B. L. Crowder, G. W. Cole, J. E. E. Bagl in and B. J. Masters, "Boron Atom Distributions in Ion-Implanted Silicon by the $(n, 4 \mathrm{He})$ Nuclear Reaction," Appl. Phys. Lett., Vo1. 21, pp. 16-17, 1972.
13. V. G. K. Reddf and A. Y. C. Yu, "Ion Implantation for Silicon Device Fabrication," Solid State Tech. pp. 35-41, 0ct. 1972.

14. R. A. Moline, "Ion Implanted Phosphorous in Silicon: Profiles Using C-V Analysis," J. App 1. Phys., Vol. 42, pp. 3553-3558, 1971.

15. V. G. K. Reddi and J. D. Sansbury, "Channe]ing and De-Channeling of Ion Implanted Phosphorus in Silicon," J. Appl. Phys. Vol. 44, pp. 2951-2963, July 1973.

16. F. L. Vook and H. J. Stein, "Relation of Neutron to Ion Damage Annealing in Si and Ge," Rad. Effects, Vol. 2, pp. 23-30, 1970.

17. M. D. Matthews, "Electrical and Electron Microscopy Observations on Defects in Ion Implanted Silicon," Rad. Effects, Vol. 11, pp. 167-178, 1971 .

18. D. E. Davies and S. A. Roosild, "Irradiation Defects and the Electrical Quality of Ion Implanted Silicon," Solid State Electron., Vol. 14, pp. 975-983, 1971.

19. B. L. Crowder, "On the Influence of the Amorphous Phase in Obtaining Electrical Activity of Ion Implanted Si," J. Electrochem. Soc. Vol. 115, pp. 943-952, 1971.

20. R. G. Hunsperger and 0. J. Marsh, "Electrical Properties of Zinc and Cadmium Implanted Layers in GaAs," J. Electrochem. Soc., Vol. 116, pp. 488-492, 1969.

21. R. G. Hunsperger and 0, J. Marsh, "Electrical Properties of $\mathrm{Cd}, \mathrm{Zn}$, and $\mathrm{S}$ Implanted Layers in GaAs," Rad. Effects, Vol. 6, pp. 257-262 (1970)

22. J. D.Sansbury and J.F. Gibbons, "Properties of Ion Implanted Silicon, Sulfur and Carbon in GaAs," Rad. Effects, Vol. 6, pp. 269-276, 1970.

23. F. H. Eisen, J. S. Harris, B. Welch, R. D. Pashiey, D. Sigurd, and J. W. Mayer, "Properties of Tellurium Implanted GaAs," in reference 3 . 